\title{
Evidence for Activity-Dependent Cortical Wiring: Formation of Interhemispheric Connections in Neonatal Mouse Visual Cortex Requires Projection Neuron Activity
}

\author{
Hidenobu Mizuno, ${ }^{1,2}$ Tomoo Hirano, ${ }^{1,2}$ and Yoshiaki Tagawa ${ }^{1,2}$ \\ ${ }^{1}$ Department of Biophysics, Kyoto University Graduate School of Science, Kitashirakawa-Oiwake-cho, Sakyo-ku, Kyoto 606-8502, Japan, and ${ }^{2}$ Core \\ Research for Evolutional Science and Technology, Japan Science and Technology Agency, Kawaguchi, Saitama 332-0012, Japan
}

Neuronal activity plays a pivotal role in shaping neuronal wiring. We investigated the role of neuronal activity in the formation of interhemispheric (callosal) axon projections in neonatal mouse visual cortex. Axonal labeling with enhanced green fluorescent protein (GFP) was used to demonstrate spatially organized pattern of callosal projections: GFP-labeled callosal axons from one hemisphere projected densely to a narrowly restricted region at the border between areas 17 and 18 in the contralateral hemisphere, in which they terminated in layers 1-3 and 5. This region- and layer-specific innervation pattern developed by postnatal day 15 (P15). To explore the role of neuronal activity of presynaptic and postsynaptic neurons in callosal connection development, an inwardly rectifying potassium channel, Kir2.1, was expressed in callosal projection neurons and their target postsynaptic neurons. Kir2.1 overexpression reduced the firing rate of cortical neurons. Kir2.1 overexpression in callosal projection neurons disturbed the growth of axons and their arbors that normally occurs between P7 and P13, whereas that in postsynaptic neurons had limited effect on the pattern of presynaptic callosal axon innervation. In addition, exogenous expression of a gain-of-function Kir2.1 mutant channel found in patients with a familial heart disease caused severe deficits in callosal axon projections. These results suggest that projection neuron activity plays a crucial role in interhemispheric connection development and that enhanced Kir2.1 activity can affect cortical wiring.

Key words: corpus callosum; cortical development; neuronal firing; activity-dependent; Kir2.1; genetic mutation

\section{Introduction}

Information processing in the cerebral cortex relies on precise neuronal wiring. Interhemispheric axon projections across the corpus callosum are among long-range efferent fibers derived from cortical neurons, connecting neurons in the left and right cerebral hemispheres. The pattern of interhemispheric (callosal) connections in the visual cortex (VC) is highly organized; the density of callosal connections is highest at the borders between the primary and secondary $\mathrm{VC}$, in which the vertical midline of the visual field is represented, and lowest in regions representing peripheral visual portions (Hubel and Wiesel, 1967; Shatz, 1977; Van Essen et al., 1982; Blakemore et al., 1983; Olavarria and Montero, 1984; Innocenti et al., 1986). This organized pattern of interhemispheric connections in VC is thought to ensure higher visual information processing (Stryker and Antonini, 2001) and develops during the prenatal and early postnatal periods (Olavarria et al., 1987; Innocenti and Price, 2005). Callosal axons de-

\footnotetext{
Received 0ct. 31, 2006; revised April 23, 2007; accepted May 7, 2007.

This work was supported in part by research grants from the Ministry of Education, Culture, Sports, Science, and Technology of Japan (T.H., Y.T.) and the Naito Foundation (Y.T.). We thank Gen Ohtsuki for help with the electrophysiology experiments and Carla J. Shatz, Yasuto Tanabe, and Shinya Kawaguchi for valuable comments on a previous version of this manuscript.

Correspondence should be addressed to Yoshiaki Tagawa, Department of Biophysics, Kyoto University Graduate School of Science, Kitashirakawa-Oiwake-cho, Sakyo-ku, Kyoto 606-8502, Japan. E-mail: tagawa@neurosci.biophys.kyoto-u.ac.jp.

DOI:10.1523/JNEUROSCI.1215-07.2007

Copyright $\odot 2007$ Society for Neuroscience $\quad$ 0270-6474/07/276760-11\$15.00/0
}

rive from neurons in cortical layers $2 / 3$ and 5. During development, they take a route to the midline and cross it. They grow further in the white matter (WM) of the contralateral cortex, locate their neocortical target area, then turn to grow into the cortical layers and make synaptic connections in the correct cortical layers (mainly layers 1-3 and 5). Many molecules, including guidance factors, are involved in the pathfinding of callosal axons (Lindwall et al., 2007).

In cortical connection development, it is generally accepted that, after an early phase of axon pathfinding involving guidance factors and molecular cues, there is a later phase that requires neuronal activity (Goodman and Shatz, 1993; Katz and Crowley, 2002; Lopez-Bendito and Molnar, 2003; Ruthazer and Cline, 2004; Sur and Rubenstein, 2005; Price et al., 2006). The role of neuronal activity in wiring of the VC has been extensively studied in the thalamocortical projections from the lateral geniculate nucleus to cortical layer 4 . Visual deprivation alters terminal arborization of geniculocortical axons within layer 4 (LeVay et al., 1980; Wiesel, 1982; Antonini and Stryker, 1996). Blockade of electrical activity in the retina, and that in the cortex, also affect thalamocortical projections (Stryker and Harris, 1986; Antonini and Stryker, 1993; Herrmann and Shatz, 1995). The development of intracortical long-range horizontal connections in layer $2 / 3$, precisely linking cortical columns with similar preferred orientations, is also influenced by visual deprivation, strabismus, and cortical activity blockade (Callaway and Katz, 1991; Lowel and Singer, 1992; Ruthazer and Stryker, 1996). These results suggest 
that both visual experience and spontaneous neuronal activity in the visual pathway are required for certain stages of cortical wiring (Katz and Shatz, 1996). As for callosal connections, previous reports suggest the involvement of visual experience in their formation and/or maintenance (Innocenti and Frost, 1979; Rhoades and Dellacroce, 1980; Cusick and Lund, 1982; Olavarria et al., 1987; Fish et al., 1991; Zufferey et al., 1999; Innocenti and Price, 2005; Olavarria and Safaeian, 2006). However, the role of neuronal activity generated within the cortex, including that of callosal projection neurons themselves and of their target postsynaptic neurons, has not been studied. Moreover, the precise period when such neuronal activity is critical for callosal axon development is unknown.

Here, the role of neuronal activity in the formation of callosal projections in the neonatal mouse VC was examined. An in utero electroporation-mediated gene transfer method was used to express enhanced green fluorescent protein (GFP) in callosal projection neurons to visualize callosal axon fibers. Using Kir2.1 as a tool to suppress firing activity of cortical neurons, we found that activity of projection neurons during the early postnatal period is crucial for establishing interhemispheric connections.

\section{Materials and Methods}

Plasmids. All genes were expressed under the control of the CAG promoter (Niwa et al., 1991). The pCAsalEGFP vector (Horikawa and Takeichi, 2001) was used for expression of enhanced GFP. Discosoma red 2 (DsRed2) was purchased from Clontech (Mountain View, CA). Kir2.1 cDNA was cloned by PCR from postnatal day 30 (P30) mouse brain cDNA with the forward F1 (5'-CCGAATTCACCATGGGCAGTGTGAGAACCA- $\left.3^{\prime}\right)$ and reverse R1 (5'-GGGGATCCTCATATCTCCGATTCTCGCCTT- $3^{\prime}$ ) primer pair. The D71V mutation was constructed by PCR using the D71V-F (5'-CAGAGGTACCTGGCAGTGATCTTTACTACC-3') and R1 primer pair. The resulting PCR product was ligated into the KpnI/BamHI site of cloned wild-type $($ WT) Kir2.1. The del314-315SY, 144-146GYG $\rightarrow$ AAA, and V93I mutations were constructed from two overlapping PCR products. For del314315 SY, product 1 was generated with the F1 and del314-315SY-R (5' -CAGAGAATTTCATTGGCCAGACTCCGGCATTGAGTTGTC-3') primer pair, and product 2 was generated with the del314-315SY-F ( $5^{\prime}$ GACAACTCAATGCCGGAGTCTGGCCAATGAAATTCTCTG-3' ) and R1 primer pair. For $144-146 \mathrm{GYG} \rightarrow \mathrm{AAA}$, product 1 was generated with the $\mathrm{F} 1$ and $144-146 \mathrm{GYG} \rightarrow$ AAA-R $\left(5^{\prime}\right.$-CACACACCTGAAAGCAGCGGCAATGGTTGT- $3^{\prime}$ ) primer pair, and product 2 was generated with the 144-146GYG $\rightarrow$ AAA-F (5'-ACAACCATTGCCGCTGCTTTCAGGTGTGTG-3') and R1 primer pair. For V93I, product 1 was generated with the $\mathrm{F} 1$ and V93I-R (5' -AGCCAGGAGAGGATGAAGGCAAGACAGAAG-3') primer pair, and product 2 was generated with the V93I-F ( $5^{\prime}$-CTTCTGTCTTGCCTTCATCCTCTCCTGGCT-3') and R1 primer pair. To generate each clone, the respective PCR products were combined and reamplified using the outside primers F1 and R1. WT Kir2.1 and all Kir2.1 mutants were ligated into the EcoRI/BamHI site of the pCAGplay vector (Kawaguchi and Hirano, 2006). All clones were verified by sequencing.

Animals. The ICR strain of mice was used. All experiments were performed according to the guidelines for animal experimentation by the National Institutes of Health (United States) and Kyoto University. All procedures were approved by the local committee for handling experimental animals at the Graduate School of Science, Kyoto University.

In vivo electroporation for pregnant mice. In utero electroporation was performed as described previously (Saito and Nakatsuji, 2001; Tabata and Nakajima, 2001). Briefly, pregnant mice at embryonic day 15.5 (E15.5) were anesthetized with Nembutal $(50 \mathrm{mg} / \mathrm{kg}$ body weight; Abbott Laboratories, North Chicago, IL) in saline. A midline laparotomy was performed to expose the uterus. For DNA microinjection, glass capillary tubes (GC150TF-10; Harvard Apparatus, Holliston, MA) were pulled using a micropipette puller (Narishige, Tokyo, Japan). One microliter of DNA solution $(0.5-1.0 \mathrm{mg} / \mathrm{ml})$ was injected into the right lateral ventri- cle of embryos, and square electric pulses ( $50 \mathrm{mV} ; 50 \mathrm{~ms}$ ) were delivered five times at the rate of one pulse per second by an electroporator (CUY21EDIT; NepaGene, Chiba, Japan). For electroporation to both hemispheres (see Fig. $7 A, B$ ), the first electroporation was performed into the right lateral ventricle as described above, and then $1 \mu \mathrm{l}$ of DNA solution was injected into the left lateral ventricle and square electric pulses were delivered. After electroporation, the uterus was repositioned, and the abdominal wall and skin were sutured. After birth, animals were anesthetized with Nembutal and decapitated at P3, P5, P7, P9, P10, P13, $\mathrm{P} 15$, and P34. Brains with relatively high GFP expression over the posterior cortex were used for experiments.

Immunohistochemistry. Brains were fixed with $4 \%$ paraformaldehyde (PFA) in PBS overnight and then transferred to $30 \%$ sucrose in PBS for $1-2 \mathrm{~d}$. Coronal and tangential brain slices $(50 \mu \mathrm{m})$ were sectioned with a freezing microtome (LM2000R; Leica, Nussloch, Germany). After permeabilization and blocking in $0.2 \%$ Triton $\mathrm{X}-100 / 5 \%$ normal goat or donkey serum (Sigma, St. Louis, MO) in PBS (blocking solution), samples were processed for immunohistochemistry. Primary and secondary antibodies were as follows: chicken anti-GFP (1:600 in blocking solution; Chemicon, Temecula, CA), rabbit anti-GFP (1:1000; Invitrogen, Carlsbad, CA), mouse anti-neuronal-specific nuclear protein (NeuN) (1:500; Chemicon), goat anti-Brain-1 (Brn-1) (1:100; Santa Cruz Biotechnology, Santa Cruz, CA), and Alexa 488-conjugated goat anti-chicken IgG, Alexa 568-conjugated goat anti-mouse IgG, Alexa 488-conjugated donkey anti-rabbit IgG, and Alexa 568-conjugated donkey anti-goat IgG (1:1000; Invitrogen). 4',6-Diamidino-2-phenylindole (DAPI) was used to assess cortical architecture.

Wheat germ agglutinin-conjugated horseradish peroxidase labeling. P30 mice were anesthetized with ketamine $(90 \mathrm{mg} / \mathrm{kg})$ and xylazine $(20 \mathrm{mg} /$ $\mathrm{kg}$ ) in saline. A craniotomy was performed, and four small evenly spaced holes were drilled in the skull across the posterior surface of one hemisphere. A Hamilton syringe was inserted into the brain through the holes $(\sim 500 \mu \mathrm{m}$ in depth), and $2 \mu \mathrm{l}$ of wheat germ agglutinin-conjugated horseradish peroxidase (WGA-HRP) $(1.5 \mathrm{mg} / \mathrm{ml}$ in saline; Vector Laboratories, Burlingame, CA) was injected. Four days after the injection, animals were anesthetized with Nembutal and decapitated. Brains were removed and fixed with $1.25 \%$ glutaraldehyde/1\% PFA in PBS and then transferred to $30 \%$ sucrose in PBS for 1-2 d. Coronal and tangential brain slices $(50 \mu \mathrm{m})$ were sectioned. HRP histochemistry was performed as described by Mesulam (1978). 5,5',3,3'-Tetramethyl-benzidine (2 mg/ $\mathrm{ml}$; Sigma) was used as the chromogen.

Electrophysiology. Coronal slices containing the visual cortex were prepared from electroporated mice at P7. Animals were anesthetized with diethylether and decapitated. Their brains were quickly removed and placed in ice cold Krebs' solution containing the following (in $\mathrm{mM}$ ): 124 $\mathrm{NaCl}, 1.8 \mathrm{KCl}, 1.24 \mathrm{KH}_{2} \mathrm{PO}_{4}, 1.3 \mathrm{MgCl}_{2}, 2.5 \mathrm{CaCl}_{2}, 26 \mathrm{NaHCO}_{3}$, and 10 glucose (saturated with $95 \% \mathrm{O}_{2}$ and $\left.5 \% \mathrm{CO}_{2}\right)$. Slices $(400 \mu \mathrm{m}$ ) were cut on a vibratome in ice-cold $130 \mathrm{~mm} \mathrm{NaCl}, 4.5 \mathrm{~mm} \mathrm{KCl}, 2 \mathrm{~mm} \mathrm{CaCl}_{2}, 33 \mathrm{~mm}$ glucose, and $5 \mathrm{~mm}$ HEPES, pH 7.4 (RDS solution). Slices were maintained at room temperature $\left(25^{\circ} \mathrm{C}\right)$ in Krebs' solution. Spontaneous spiking of GFP-positive layer $2 / 3$ pyramidal cells was recorded using the cell-attached patch-clamp method. Patch pipettes were filled with Krebs' solution and had resistances of 4-5 M $\Omega$. Electrophysiological recording was performed with an EPC-9 amplifier (HEKA Elektronik, Lambrecht, Germany).

Microscopy. The projection patterns of GFP-labeled callosal axons were analyzed using a LSM510 confocal laser scanning microscope (Zeiss, Oberkochen, Germany). For each tissue section (50 $\mu \mathrm{m}$ in thickness), serial confocal images were collected at $3 \mu \mathrm{m}$ intervals to create a $z$-axis image stack.

Densitometric line scans of GFP signals across cortical layers. Quantitative line scan analyses (see Figs. $2 D, 3 D$ ) were performed using $\mathrm{NIH}$ Image J software. For each image (e.g., the image in Fig. $2 A$ ), the centerline of the zone receiving callosal axon innervation was selected as follows. Sequential vertical lines ( 1 pixel in width) were drawn across all cortical layers, and the average signal intensity of pixels along each line was calculated. The line with the highest average signal intensity was defined as the centerline of the callosal axon innervation zone. At every pixel along this centerline, sequential perpendicular lines $500 \mu \mathrm{m}$ in 
length were generated from the cortical surface toward the bottom of the WM, and the average signal intensity of pixels along each perpendicular line was calculated. A background level of signal was computed in adjacent areas of cortex and subtracted. The resulting density line scan generated a plot of GFP signal intensity versus distance from the cortical surface. To compensate for variability in the efficacy of labeling callosal axons with GFP, the average WM GFP signal intensity was calculated for each plot and used to normalize the signal intensity at each point. Then, scans from the same group were aligned and averaged to generate a plot of averaged line scans. The numbers of sections for densitometric line scans were as follows: for Figure 2D, GFP, 5 (P10), 5 (P13), and 8 (P15); for Figure $3 D$, GFP, 8, GFP plus Kir2.1, 9. One section was used per animal; therefore, the numbers of sections are equal to those of animals used.

Quantification of GFP signals in layers 1-3 and 5. The normalized GFP signal intensity in layers $1-3$ or 5 was calculated as follows. The centerline of the callosal axon innervation zone was selected using the method described above. Based on this centerline, three boxes $(500 \mu \mathrm{m}$ in width, $200 \mu \mathrm{m}$ in height) were drawn to enclose the GFP-labeled callosal axon fibers in layers 1-3, layer 5, and the WM. The density of GFP signal in each box was computed. The normalized GFP signal intensity in layers 1-3 and 5 was calculated by dividing the signal from layers $1-3$ or 5 by the WM signal. The numbers of sections for quantification were as follows: for Fig. 3, GFP, 8, GFP plus Kir2.1, 9; for Fig. 5, GFP, 5 (P10), 5 (P13), and 8 (P15), GFP plus Kir2.1, 7 (P10), 5 (P13), and 9 (P15); for Fig. 6, GFP, 8, D71V, 5, del314-315SY, 6, 144$146 \mathrm{GYG} \rightarrow$ AAA, 6, V93I, 5, WT Kir2.1, 9; for Figure 7, control, 6 , postsynaptic activity blockade, 7 . Each animal was represented as one section.

\section{Results}

\section{Axonal projection patterns of callosal} neurons labeled with GFP

An in utero electroporation-mediated gene transfer method was used to express GFP in layer $2 / 3$ callosal projection neurons for assessment of the tangential and laminar distribution of their axon terminals with high resolution. Mouse embryos were electroporated with a GFP expression plasmid on E15.5, an age when efficient and specific gene transfer into cortical layer $2 / 3$ neurons has been reported previously (Saito and Nakatsuji, 2001; Tabata and Nakajima, 2001). We focused on layer $2 / 3$ callosal projection neurons because the majority of callosal fibers derive from these neurons (Jacobson and Trojanowski, 1974). The GFP expression plasmid was introduced into neurons in the caudal part of the right hemisphere and callosal fiber projections to the contralateral (left) hemisphere were analyzed at various postnatal ages.

In the electroporated side of the cortex, bright fluorescent GFP signals were present across the entire mediolateral extent at P15 (Fig. 1A). Double immunohistochemistry using anti-GFP and anti-NeuN antibody (a marker for neuronal cells) revealed that GFP-positive neurons were confined to layer $2 / 3$ (Fig. $1 B$ ). GFP-labeled axons originating from cell bodies ran ventrally to-
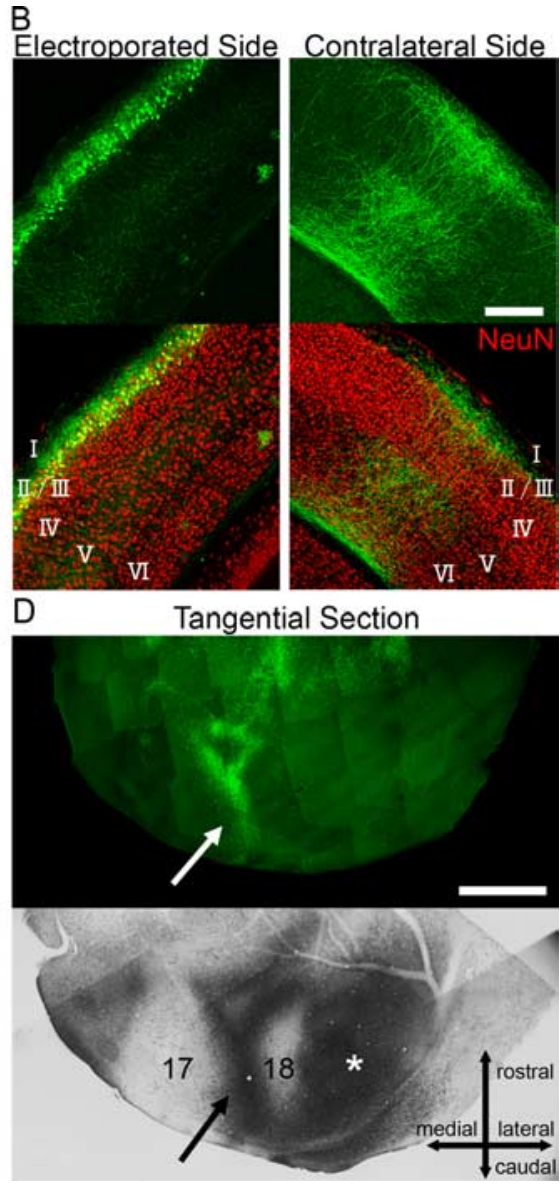

Figure 1. Tangential and laminar distribution of interhemispheric axon projections in the mouse visual cortex visualized using GFP. A, A coronal section through the P15 visual cortex shows the distribution of neurons expressing GFP and their axon projections. An in utero electroporation-mediated gene transfer method (EP) was used to unilaterally express GFP in cortical neurons ( , schematic drawing of a callosal axon projection. $\boldsymbol{B}$, Higher-magnification confocal images show the laminar distribution extensively in layers 1-3 and 5.C, D, Comparison of GFP labeling and WGA-HRP tract tracing of callosal axon projections in coronal antial (D) sections from P34 mice. WGA-HRP was used as another means of delineating the organization of callosa the border between areas 17 and 18. Note the similar distribution pattern of WGA-HRP labeling in the visual cortex (arrows in bottom panels). Asterisks indicate WGA-HRP labeling in the auditory cortex. Scale bars: $A, C, 1 \mathrm{~mm} ; \boldsymbol{B}, 200 \mu \mathrm{m} ; \boldsymbol{D}, 2 \mathrm{~mm}$.

ward the WM with extensive arborization in layer 5 before reaching the WM (Fig. $1 A, B$ ). Some of the axons turned laterally, whereas others turned toward the midline and fasciculated to form the corpus callosum. In the contralateral cortex, GFPlabeled axon fibers ran through the WM, and then most made an abrupt turn toward the cortical surface and formed terminal arborizations (Fig. 1A,B). Higher-resolution confocal imaging revealed that axonal arborizations were heavy in two bands of cortex corresponding to layers $1-3$ and 5 and sparse in layers 4 and 6 (Fig. $1 B$ ) (see Fig. $2 A$ ), consistent with previous observations that callosal fibers form synaptic connections mainly with layer $2 / 3$ and 5 neurons (Aggoun-Zouaoui et al., 1996).

In the caudal part of the cortex, terminals of GFP-labeled axons appeared restricted to the border between the primary and secondary VC (area 17 and 18, respectively). To further assess this innervation pattern, the pattern of GFP-labeled callosal axon 

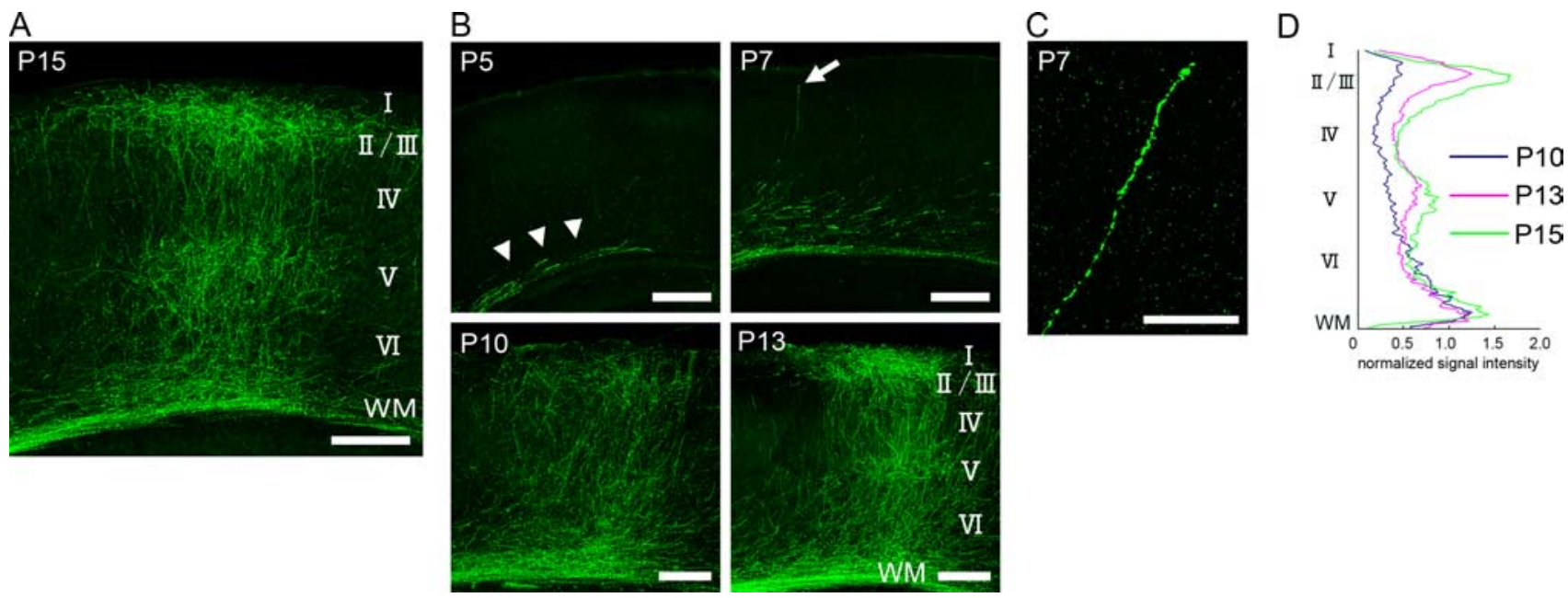

Figure 2. Region- and layer-specific innervation patterns develop between P5 and P15. A, The mature terminal arborization pattern of callosal axons in the visual cortex at P15. B, Distribution of callosal axons and their arbors in the visual cortex at P5, P7, P10, and P13. Arrowheads show GFP-labeled callosal axon terminals in the WM at P5. Some fibers reached layer 1 by P7 (arrow). Later (P10 and P13), numerous fibers were observed across all cortical layers. Note extensive growth of axon arbors in layers $1-3$ and 5 between P10 and P13. C, An enlarged terminal of a callosal axon in cortical layer 1 at P7. D, Densitometric line scans of GFP fluorescence intensity across all cortical layers in P10, P13, and P15 sections. Five to eight sections were scanned for each age. Scale bars: $A, B, 200 \mu \mathrm{m} ; C, 30 \mu \mathrm{m}$.

projections was compared with the distribution of callosal connections assessed by a tract tracer, WGA-HRP, in coronal and tangential P34 sections (Fig. 1C,D). Solution containing WGAHRP was injected into multiple sites spaced evenly across the posterior surface of one cortical hemisphere at P30, and the distribution of WGA-HRP labeling in the other hemisphere was assessed by HRP histochemistry at P34. As expected from previous results in rodents (Olavarria and Van Sluyters, 1984), a dense band labeled with WGA-HRP was present at the 17/18 border, with almost no labeling in the medial part of the primary VC (Fig. $1 C, D)$. This pattern was similar to the projection pattern of GFPlabeled callosal axons. Because WGA-HRP injected into the cortex is taken up by both cell bodies and axon terminals located near the injection site, it labels terminals of callosal axons projecting from the dye-injected hemisphere (anterograde labeling) as well as cell bodies of callosal neurons projecting to the dyeinjected hemisphere (retrograde labeling). In contrast, GFP solely labels the former. This could account for the seemingly narrower distribution of GFP-labeled axon terminals seen in Figure 1, $C$ and $D$. Together, these observations show that the tangential and laminar distribution of callosal axon projections assessed by GFP resembles the known pattern of callosal connections in mouse VC (Olavarria and Van Sluyters, 1984). Moreover, these results indicate that the in utero electroporationmediated gene transfer method can be used to assess region- and layer-specific innervation patterns of interhemispheric axons in the mouse VC. In the subsequent experiments, the development of callosal connections in the caudal region (including the $\mathrm{VC}$ ) was studied.

\section{Development of visual callosal projections during the early postnatal period}

Information about how individual callosal axons form their mature terminal arborization pattern is limited in rodents. Therefore, we labeled individual mouse callosal fibers with GFP and examined their development at various postnatal ages. Callosal fibers were present in the WM beneath the primary VC by P3 (data not shown). At P5, most of the axon terminals remained in the WM and the subplate (Fig. $2 B$ ). There was a period of $2-3 \mathrm{~d}$ between the arrival of axons and the onset of their invasion into the cortical plate. This time lag would correspond to the "waiting period" (Fish et al., 1991; Aggoun-Zouaoui and Innocenti, 1994), a period when growing axons explore and locate their target innervation area. By P7, several fibers had reached the marginal zone (layer 1). Because axons penetrating the cortical layers were sparse at this age, individual fibers could be traced to the marginal zone. Axons ran radially with almost no branching, and most of them ended in enlarged terminals (Fig. 2B, C).

The morphology of callosal axon terminal arbors changed dramatically between P7 and P13. At P10, many GFP-positive fibers had reached layer 1 , and numerous fibers and branches were intermingled (Fig. 2B). GFP-labeled axons and branches displayed a relatively even distribution across all cortical layers at this age. At P13, laminar specificity of axonal arborizations was apparent; terminal arbors in layers 1-3 were numerous and extensive, with some ramifications in layer 5 (Fig. $2 \mathrm{~B}$ ). Thus, between P10 and P13, the density of GFP-positive fibers increased robustly in layers $1-3$, moderately in layers 4 and 6 , and intermediately in layer 5 (Fig. $2 B$ ). The overall distribution of GFPpositive fibers across cortical layers was similar at P13, P15, and thereafter (Fig. 2A, B, and data not shown).

To quantify these observations, line scan analyses were performed. Densitometric line scans were made from all cortical layers along the callosal axon innervation zone to generate a plot of GFP signal intensity versus distance from the cortical surface (GFP signal intensity at each point was normalized to the average GFP signal intensity in the WM; for details, see Materials and Methods). Averaged line scans at P15 reveal a peak in the GFP signal in layers $1-3$, a small peak in layer 5 , and another peak in the WM (Fig. 2D), a pattern reflecting the distribution of GFPlabeled axons shown in Figure $2 \mathrm{~A}$. Similar analyses over a range of postnatal ages demonstrated extensive laminar-selective growth of callosal axon arbors between P10 and P15 (Fig. 2D). A laminar specific innervation pattern emerged sharply between P10 and P13. GFP intensity in layers $1-3$ increased 2.5-fold between P10 and P13 and 3.5-fold between P10 and P15, reflecting intense growth and arborization of GFP-labeled callosal axons in layers 1-3 during this period (peak values in Fig. 2D: P10, 0.49; 
P13, 1.25; P15, 1.67). Collectively, these observations indicate that the region- and layer-specific innervation patterns of callosal axons develop dynamically between P3 and P15.

\section{Suppression of neuronal activity in callosal neurons affects their axon projections}

Spontaneous bursting of developing cortical neurons during the prenatal and early postnatal periods is thought to play a role in establishing, maintaining, and remodeling cortical connectivity (Yuste et al., 1995; Katz and Shatz, 1996; Owens et al., 1996; Adelsberger et al., 2005; Khazipov and Luhmann, 2006). However, the precise role(s) of such neuronal activity in cortical wiring remains elusive. To determine the role of neuronal activity in the development of interhemispheric connections, an inward rectifier $\mathrm{K}^{+}$channel, Kir2.1, was used as a genetic tool to electrically silence neurons (Johns et al., 1999; Burrone et al., 2002; Yu et al., 2004; Hua et al., 2005). Exogenous expression of Kir2.1 in neurons decreases excitability, thereby reducing the firing rate of the neurons (Burrone et al., 2002; Hua et al., 2005). A GFP expression plasmid with or without a Kir2.1 expression vector was transfected into the cortex at E15.5 by in utero electroporation (Fig. 3A). Cortical slices were prepared at P7, and cellattached patch-clamp recording was performed to measure spike-firing rates of GFP-positive neurons in layer 2/3. Firing frequency was assessed at P7 because, at this age, GFP-expressing "control" neurons in our slice preparations fired sufficient numbers of action potentials (mean firing rate at P5, $0.08 \pm 0.02 \mathrm{~Hz}$; $\mathrm{P} 7,0.16 \pm 0.04 \mathrm{~Hz} ; \mathrm{P} 10,0.10 \pm 0.03 ; n=9,21$, and 14 neurons for P5, P7, and P10, respectively). As shown in Figure 3B, exogenous expression of Kir2.1 in layer $2 / 3$ cortical neurons significantly reduced their firing rates at P7 (GFP, $0.16 \pm 0.04 \mathrm{~Hz}$; GFP plus Kir2.1, $0.07 \pm 0.03 \mathrm{~Hz} ; n=21$ neurons for each group; $p=$ 0.002 , Mann-Whitney test), suggesting that Kir2.1 expression suppresses cellular excitability.

Previous work has shown that multiple plasmids can be introduced into the same cells by in utero electroporation (Hatanaka et al., 2004; Torii and Levitt, 2005; Matsuda and Cepko, 2007). In our hands, when a mixture of plasmids encoding green (GFP) and red (DsRed2) fluorescent proteins was used for electroporation, almost all GFP-positive neurons coexpressed DsRed2 (96\%) (supplemental Fig. 1, available at www.jneurosci.org as supplemental material). Thus, when a mixture of GFP and Kir2.1 plasmids is transfected, it is likely that GFP-positive callosal fibers derive from neurons that also express Kir2.1. The tangential and laminar distributions of axonal projections of Kir2.1 expressing callosal neurons were analyzed at P15 (Fig. 3C). Comparable numbers of GFP-labeled fibers appeared to arrive in the region of the 17/18 border (Fig. 3C, see GFP-labeled callosal axon fibers in the WM). However, terminal arborizations in layers 1-3 were greatly reduced by Kir2.1. Quantitative line scan analyses demonstrated that Kir2.1 expression decreased the average signal intensity of GFP in layers $1-3$ by $50 \%$ (Fig. 3D, values normalized to
WM signal intensity: GFP, $1.47 \pm 0.27$; GFP plus Kir2.1, $0.69 \pm$ $0.10 ; n=8$ and 9 sections from 8 and 9 animals for GFP and GFP plus Kir2.1, respectively; $p=0.003$, Mann-Whitney test). In contrast, GFP signals in layer 5 were not significantly affected, as shown in the representative image (Fig. $3 C$ ) and line scans (Fig. 3D: GFP, $0.86 \pm 0.10$; GFP plus Kir2.1, $0.70 \pm 0.07 ; n=8$ and 9 for GFP and GFP plus Kir2.1, respectively; $p=0.211$ ). Notably, axons remaining in layers 5 and 1-3 still localized in a spatially restricted zone at the border between areas 17 and 18 (Fig. 3C), implying that region-specific axon targeting was not perturbed by the activity blockade. Thus, exogenous expression of Kir2.1 in callosal neurons selectively impaired axon projections to layers 1-3.

\section{Neuronal identity, migration, and axonal extension are not} affected by exogenous Kir2.1 expression

Exogenous Kir2.1 expression in callosal projection neurons could alter specification of neuronal identity, which might account for impaired axonal projections. This possibility was unlikely, however, because of the following observations. Double immunostaining with anti-GFP and anti-NeuN antibody in the electroporated hemisphere showed that Kir2.1-transfected neurons resided in the correct cortical layer (i.e., layer 2/3) (Fig. 4A). Furthermore, Kir2.1-transfected neurons expressed a layer 2/3selective marker, Brn-1, as control neurons (McEvilly et al., 2002; Fukumitsu et al., 2006) (Fig. 4B). These results suggest normal migration, positioning, and specification of Kir2.1-expressing neurons in the cortex. Massive cortical cell death in response to exogenous Kir2.1 expression could also account for the reduced number of callosal axons. This possibility was excluded by two observations. First, the number of GFP-positive neurons in the electroporated hemisphere did not change significantly with 
A

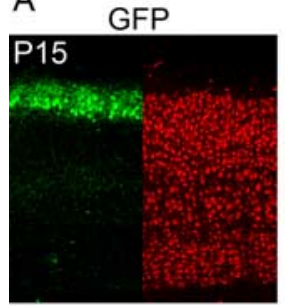

B GFP

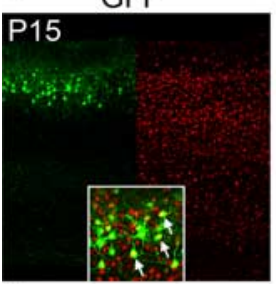

$\mathrm{D}$

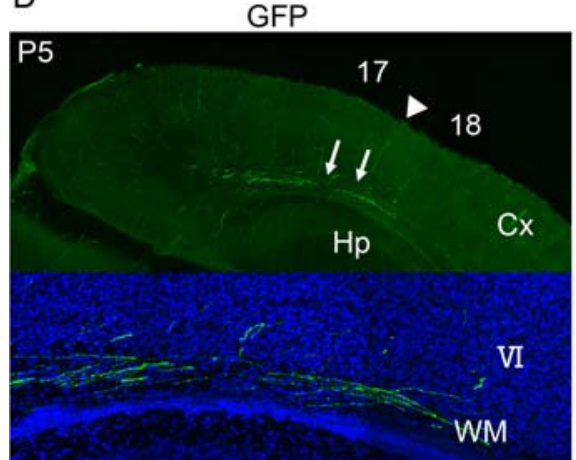

C

GFP + Kir2.1

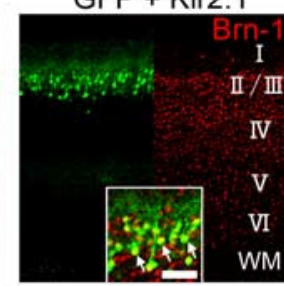

WM

V
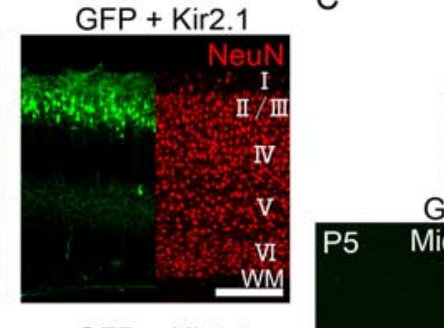

GFP
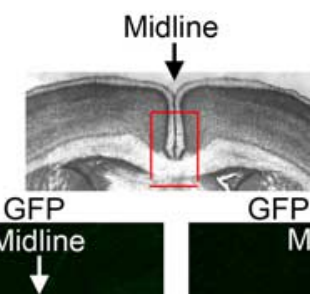

$\downarrow$
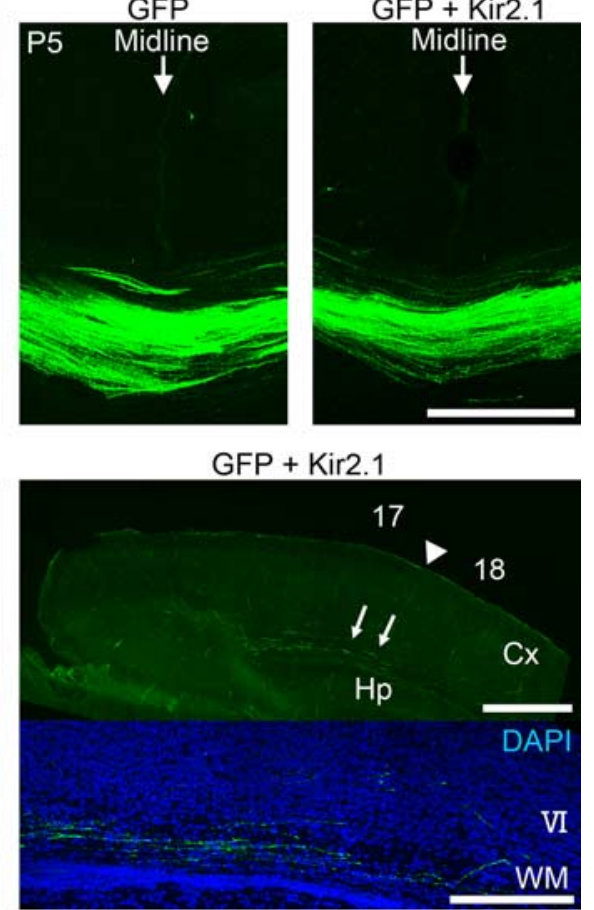

Figure 4. Exogenous expression of Kir2.1 in layer 2/3 cortical neurons does not affect their neuronal identity, migration, or axonal extension. A, Immunostaining using anti-NeuN antibody (red) showed that Kir2.1-transfected neurons (GFP-labeled cell bodies in the right) resided in the correct cortical layer. GFP electroporation was performed at E15.5; images from P15 cortical sections. Scale bar, $200 \mu \mathrm{m} . \boldsymbol{B}$, Immunostaining using anti-Brn-1 antibody (red) showed that Kir2.1-transfected neurons expressed the transcription factor Brn-1. Brn-1 is involved in neuronal identity specification. Arrows in the insets indicate GFPlabeled cell bodies expressing Brn-1. Scale bar, $50 \mu \mathrm{m}$. C, Numerous GFP-labeled axons expressing Kir2.1 crossed the midline and projected to the contralateral cortex in a fasciculated tract at P5. Scale bar, $500 \mu \mathrm{m}$. D, GFP-labeled axons reached the 17/18 border by P5 (left). There was no apparent developmental delay in the arrival of axons expressing Kir2.1 (right). Arrows indicate callosal axon fibers. Arrowheads indicate the border between areas 17 and 18. In the bottom panels, DAPI staining was used to show cortical layers. Hp, Hippocampus; Cx, cerebral cortex. Scale bars: top, $500 \mu \mathrm{m}$; bottom, $200 \mu \mathrm{m}$.

Kir2.1 expression (Fig. 4A). Second, as assessed by terminal deoxynucleotidyl transferase-mediated dUTP nick end labeling staining (Gavrieli et al., 1992), Kir2.1 expression did not increase the number of cells undergoing apoptosis (data not shown).

Axonal extension to the target area was not impaired by exogenous Kir2.1 expression. It appeared that comparable numbers of GFP-labeled callosal axons crossed the midline (Fig. 4C). Tips of axons of Kir2.1-expressing callosal projection neurons reached $17 / 18$ border by P5, with no apparent developmental delay compared with control axons (Fig. 4D). Collectively, these findings suggest that exogenous Kir2.1 expression in callosal projection neurons does not affect neuronal specification, migration, cellular viability, axon extension, or region-specific axon targeting.

\section{Development of axons and their arbors in activity-suppressed} callosal neurons

As shown in Figure 2, callosal axons develop in several successive stages. To determine which stage is susceptible to activity blockade, we analyzed axon arbor development of callosal neurons expressing Kir2.1. The effects of reduced excitability were evident at P10 (Fig. 5A). In control P10 mice, numerous GFP-labeled axon fibers were found in layers 1-3. In contrast, GFP-labeled fibers in layers 1-3 were sparse in mice electroporated with Kir2.1. Higherresolution confocal imaging in control P9 mice demonstrated that numerous axons and their branches were intermingled (Fig. 5B), and some fibers were running horizontally or obliquely. In contrast, the morphology of axons of callosal neurons expressing Kir2.1 was simpler. They extended straight up to layer 1 with little branching and ended in a growth conelike structure, suggestive of an immature developmental state (Fig. 5B).

The effect of the activity blockade was more evident at P13. In control mice, the density of GFP-labeled axons in layers 1-3 increased dramatically between P10 and P13, reflecting the extensive growth of axons and their arbors that normally occurs (Fig. 5A) (Fig. 2B,D). However, an increase in the number of GFP-labeled axons in layers 1-3 was not apparent in mice electroporated with Kir2.1. Consequently, the density of GFP-labeled axons in layers 1-3 was much lower than that of $\mathrm{P} 13$ controls (Fig. 5A). The ramification patterns of axons of Kir2.1-expressing neurons in layer 5 were similar, but their extent appeared slightly less than that of control mice. These visual impressions were validated quantitatively. During normal callosal axon development, the GFP signal intensity in layers 1-3 increased rapidly from P10 to P15. In contrast, GFP signal intensity in layers 1-3 remained low in mice electroporated with Kir2.1 (Fig. 5C) $(p<0.001$, ANOVA). In addition, the extent of axonal ramifications in layer 5 was transiently delayed at P13 (Fig. 5D). Thus, Kir2.1 expression in callosal projection neurons disturbed the growth of axons and their arbors that normally occurs between P7 and P13.

Kir2.1-expressing axons might have formed arbors in layers 1-3 initially, which may have subsequently been pruned. If this is the case, GFP signal intensity in layers 1-3 would increase transiently between P10 and P13. However, quantitative measurements made at P10, P11, P12, and P13 showed that GFP signal intensity in layers 1-3 remained low in mice electroporated with Kir2.1, and we never observed a transient peak of GFP signals at any time points (supplemental Fig. 2, available at www. jneurosci.org as supplemental material). Thus, it is likely that arborization did not proceed during this period in these mice. It is generally thought that neuronal activity is required for the maintenance and reorganization phases but not the initial phases of neuronal wiring in the cortex (Katz and Crowley, 2002; Innocenti and Price, 2005). Surprisingly, initial establishment of callosal connections was reduced by a neuronal activity blockade.

\section{Disease-causing Kir2.1 mutant affects development of callosal projections}

Formation of interhemispheric axon projections is severely impaired by increased expression of Kir2.1 in callosal projection neurons. We addressed what happens when Kir2.1 channel activ- 

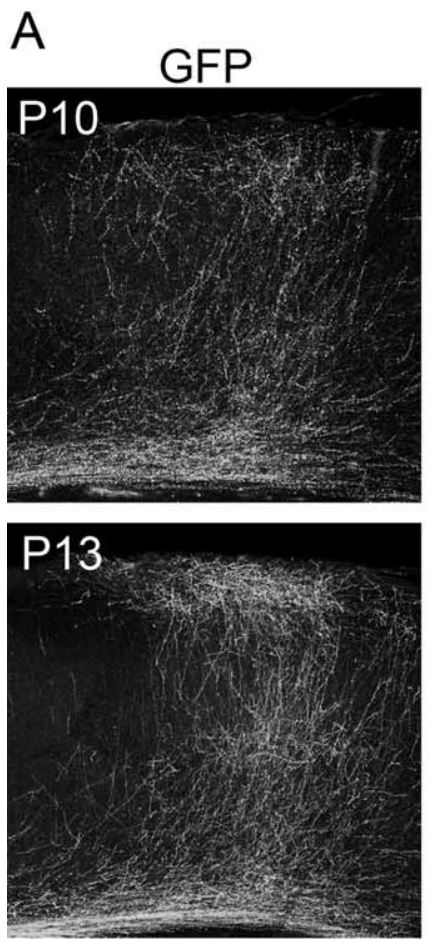

GFP + Kir2.1
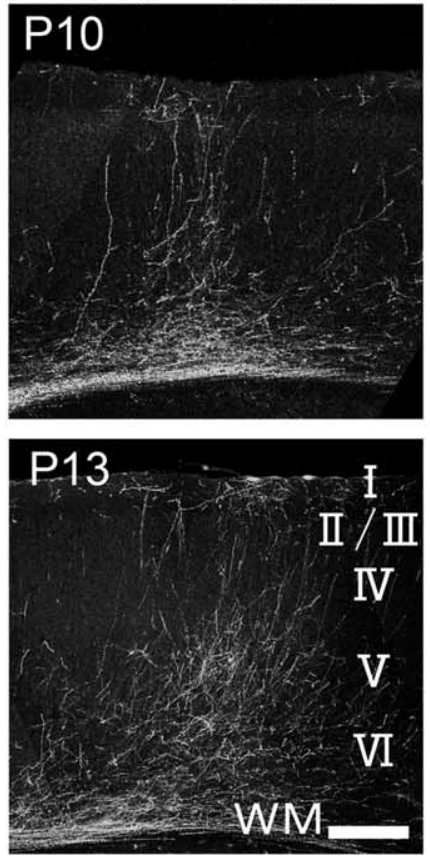

B

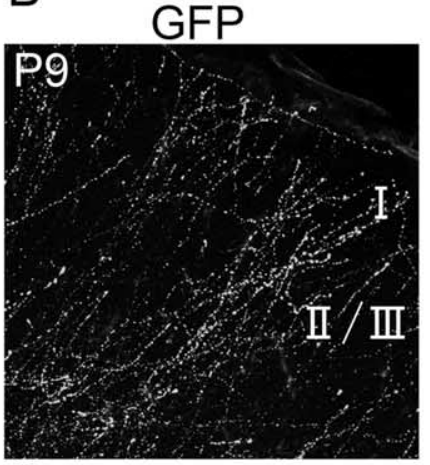

Layers 1-3

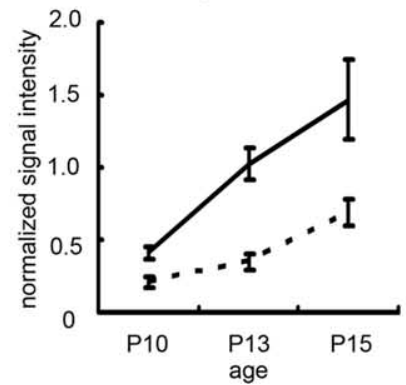

GFP + Kir2.1

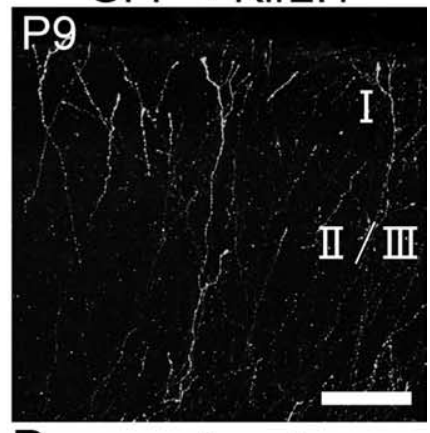

Layer 5

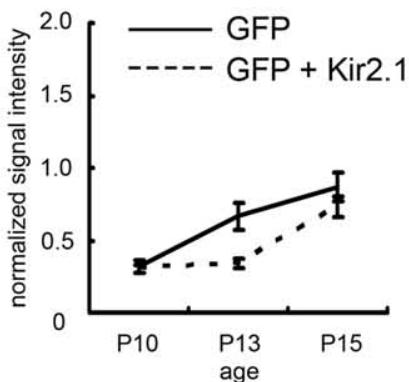

Figure 5. Blocking neuronal activity impairs growth of axons and their arbors between P10 and P15.A, Distribution of GFP-labeled callosal axons in the visual cortex at P10 (top) or P13 (bottom). Left, Normal development showing an increase in the density of GFP-labeled axons and arbors in layers $1-3$ between P10 and P13 (images reproduced from Fig. 2 B). Right, Development of axon projections in callosal neurons expressing Kir2.1. In developing neurons overexpressing Kir2.1, GFP-labeled axons were sparse in layers 1-3 at P13. B, Higher-magnification images illustrating the morphology of GFP-labeled axons and their terminals in layers 1-3 at P9. Left, GFP, Numerous intermingled axons and their branches running radially, obliquely, and horizontally. Right, GFP+ Kir2.1, Simple axon morphology with less branching and ending in a growth cone-like structure, suggestive of an immature state in development. $\boldsymbol{C}$, $\boldsymbol{D}$, In normal callosal axons, GFP intensity in layers 1-3 (C) and $5(\boldsymbol{D})$ increased rapidly between P10 and P15. In animals electroporated with Kir2.1, the extent of GFP in layers $1-3$ was consistently less than control between P10 and P15 ( $C$, and there was a transient developmental delay in layer 5 at P13 (D). Error bars represent SEM. Five to nine sections were scanned for each group. Scale bars: $\boldsymbol{A}, 200 \mu \mathrm{m} ; \boldsymbol{B}, 100 \mu \mathrm{m}$.

ity is decreased in these neurons. In other excitable tissue (e.g., skeletal and cardiac muscle), reduced Kir2.1 channel activity causes severe manifestations (Plaster et al., 2001). Endogenous levels of Kir2.1 mRNA and protein in layer 2/3 cortical neurons during perinatal and postnatal periods are relatively high (Karschin and Karschin, 1997; Miyashita and Kubo, 1997); however, its role in brain function and connectivity is unknown, partly because Kir2.1-deficient mice die shortly after birth (Zaritsky et al., 2000). Several mutant Kir2.1 channels (144-146GYG $\rightarrow$ AAA, D71V, and del314-315SY) were used to determine whether decreased expression or activity of Kir2.1 causes abnormalities in cortical development. These mutant channels are well characterized and show strong dominant-negative effects in heterologous expression systems (such as Xenopus oocytes and mammalian cell lines) (Tristani-Firouzi et al., 2002; Bendahhou et al., 2003). The $144-146$ GYG $\rightarrow$ AAA and D71V Kir2.1 mutants have a channel pore mutation and a point mutation in the first transmembrane domain, respectively; both coassemble with wild-type channels on the cell surface, thus forming nonfunctional channels and suppression of channel activity. Two amino acids in the C-terminal region have been deleted in del314-315SY, which traps wild-type Kir2.1 channels in the endoplasmic reticulum, resulting in reduced cell-surface expression of intact channels. Plasmids encoding each of these mutant Kir2.1 channels (with a GFP plasmid) were electroporated into callosal projection neurons, and axon projection patterns were assessed.

Expression of any of the three dominant-negative mutant channels did not affect the pattern of callosal connections (Fig. $6 A$ ). GFP signal intensity in layers $1-3$ was comparable in control mice and those electroporated with the Kir2.1 mutants (Fig. $6 B$ :
GFP, $1.47 \pm 0.27 ;$ D71V, $1.86 \pm 0.15$; del314-315SY, $1.44 \pm$ $0.21 ; 144-146 \mathrm{GYG} \rightarrow \mathrm{AAA}, 1.61 \pm 0.50 ; n=8,5,6$, and $6 \mathrm{sec}-$ tions for GFP, D71V, del314-315SY, and 144-146GYG $\rightarrow$ AAA, respectively). Thus, these dominant-negative mutations had limited impact on cortical connectivity.

We also tested a gain-of-function mutant, V93I, identified from families with atrial fibrillation, a cardiac disease characterized by rapid and irregular activation of the atrium (Xia et al., 2005). Expression of V93I mutant channels in the cortex did not cause any apparent abnormalities in neuronal migration or layer formation (data not shown). However, the V93I mutation did cause severe defects in callosal axon projections. Although comparable numbers of GFP-positive fibers reached the 17/18 border region (supplemental Fig. 3, available at www.jneurosci.org as supplemental material), only a very small number of fibers entered into and innervated that region (Fig. 6A). Consequently, the GFP signal intensity in layers $1-3$, which reflects the extent of callosal axon innervation, was 35\% of control in V93I electroporated mice (GFP, $1.47 \pm 0.27$; V93I, $0.51 \pm 0.09 ; n=8$ and 5 for GFP and V93I, respectively; $p=0.032$, Dunnett's $t$ test), suggesting that a gain-of-function mutation in Kir2.1 is detrimental to interhemispheric connection development.

\section{Effect of postsynaptic activity blockade on presynaptic axon projections}

The above results show that activity of projection neurons can regulate their axonal arborization. Axon terminals make synaptic contacts with postsynaptic neurons. We examined whether activity of postsynaptic neurons can also influence presynaptic axon arborization. Two sequential electroporations were performed at 


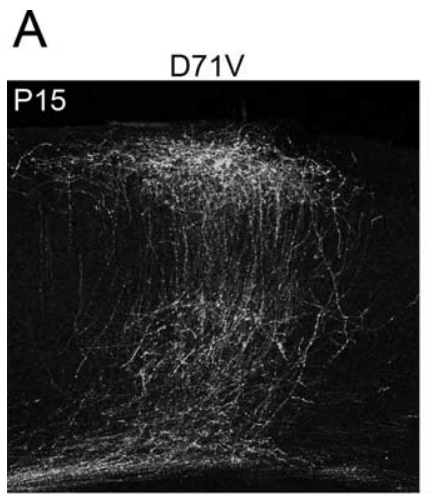

$144-146 G Y G \rightarrow$ AAA

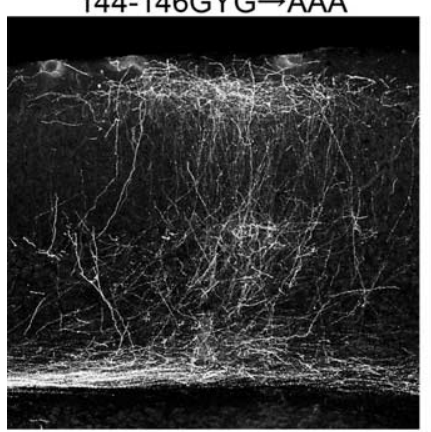

B

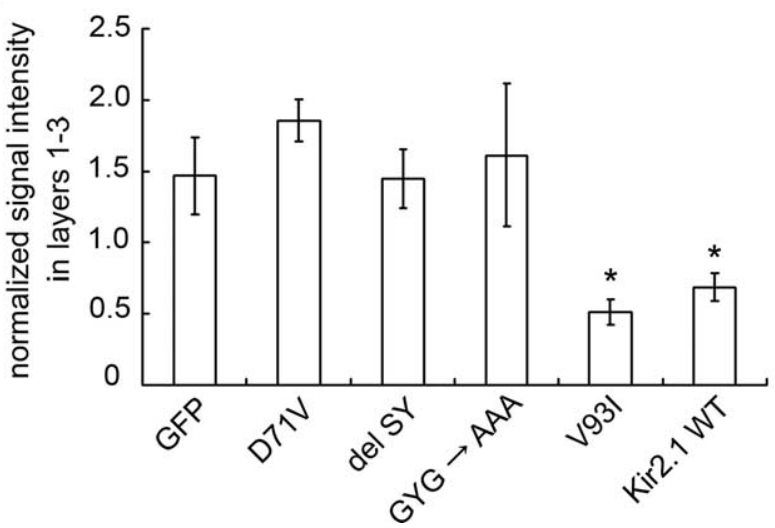

Figure 6. Effects of disease-causing mutant Kir2.1 channels on interhemispheric axon projections. $A$, Representative images of GFP-labeled callosal axons expressing mutant Kir2.1 channels. Three dominant-negative mutants (D71V, del314 -315SY, and 144-146GYG $\rightarrow$ AAA) did not affect the projection pattern of callosal axons, but a gain-of-function mutant, V93l, reduced callosal axon innervation at P15. Scale bar, $200 \mu \mathrm{m}$. B, GFP signal intensity in layers 1-3 of control animals and animals electroporated with plasmids encoding each of the mutant Kir2.1 channels. Data from animals expressing wild-type Kir2.1 are shown for comparison. Asterisks indicate statistical significance. Error bars represent SEM. Five to nine sections were scanned for each group.

E15.5: GFP plasmid into one hemisphere for labeling callosal axons, and Kir2.1 plasmid into the other hemisphere for activity blockade of putative postsynaptic neurons (Fig. 7A) (DsRed2 plasmid was mixed with Kir2.1 plasmid for assessment of the electroporated cortical domains; for details, see Materials and Methods). As shown in Figure 7B, DsRed2-labeled cells were present in layer $2 / 3$ in which GFP-labeled callosal axons made extensive terminal arborizations. Thus, this electroporation protocol allowed us to assess presynaptic arbor formation of callosal axons under postsynaptic activity blockade.

The overall innervation pattern of GFP-labeled callosal axons under postsynaptic Kir2.1 expression was comparable with that without Kir2.1 expression at P15 (Fig. 7B). Quantitative mea-
A

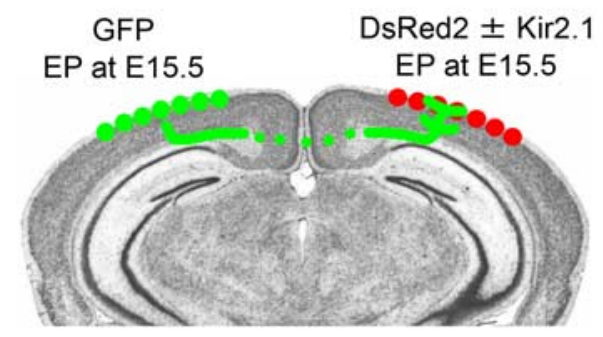

B
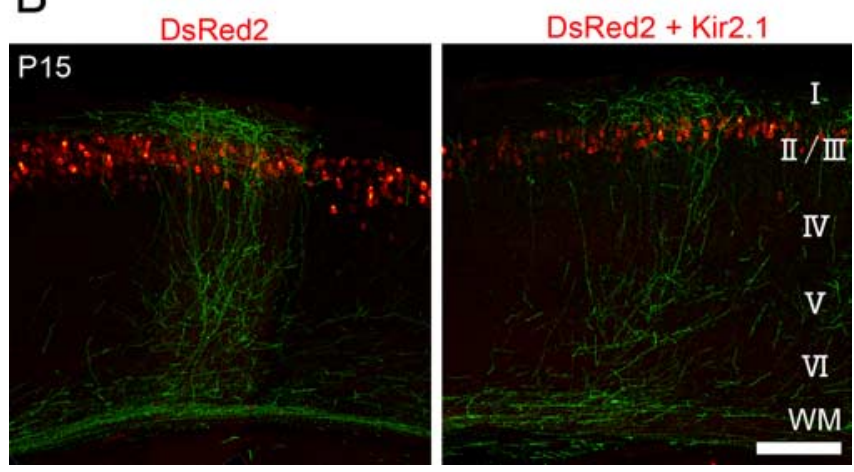

Figure 7. Effect of postsynaptic activity blockade on the pattern of presynaptic callosal axon projection. $A$, Experimental design for postsynaptic activity blockade. Two sequential electroporations were performed at E15.5. One hemisphere was electroporated with a GFP expression plasmid for labeling callosal axons and the other hemisphere with a DsRed2 expression plasmid (with or without Kir2.1 plasmid). B, The innervation pattern of GFP-labeled callosal axons in P15 cortical sections taken from the hemisphere in which DsRed2 (red) was transfected in layer $2 / 3$ (left, without Kir2.1; right, with Kir2.1). Scale bar, $200 \mu \mathrm{m}$.

surements support this visual impression; GFP signal intensity in layers $1-3$ and 5 is comparable between controls and postsynaptic activity blockade (layers 1-3: control, $1.39 \pm 0.20$; postsynaptic activity blockade, $1.43 \pm 0.30$; layer 5 : control, $0.82 \pm 0.14$; postsynaptic activity blockade, $0.86 \pm 0.12 ; n=6$ and 7 sections for controls and postsynaptic activity blockade, respectively). This result implies that postsynaptic activity blockade has limited effect on the pattern of presynaptic callosal axon innervation.

\section{Discussion}

Here we used in utero electroporation-mediated gene transfer method to explore the role of neuronal activity in interhemispheric axon development. GFP-assessed region- and layerspecific innervation patterns of interhemispheric axons were consistent with previous observations using tract tracers. Using Kir2.1 as a tool to suppress electrical activity of cortical neurons, we found that activity of projection neurons themselves plays a crucial role in callosal axon projections. In contrast to the well documented role of neuronal activity in the refinement of axonal projections and synaptic connections (Katz and Shatz, 1996; Innocenti and Price, 2005), activity blockade in callosal projection neurons disturbed the initial terminal arbor growth of their axons in layers 1-3 with less effects in layer 5, indicating that the activity of a projection neuron is required for the establishment, rather than the refinement, of callosal connections in the specific cortical layers. Exogenous expression of a gain-of-function Kir2.1 mutant channel found in patients with familial atrial fibrillation severely reduced callosal axon projections. This result implies that patients carrying certain types of genetic mutations in Kir2.1 channels may have deficits in cortical connectivity. Together, our findings suggest that certain stages of interhemispheric axon development require proper neuronal activity and 
that genetic mutations in ion channels can alter cortical connectivity through an activity-dependent mechanism.

\section{Activity-dependent and -independent stages of callosal axon development}

Previous studies using cats have shown that callosal axon projections develop in several successive stages (Innocenti, 1995; Aggoun-Zouaoui et al., 1996). Our observations indicate that similar developmental stages also exist in mice and further suggest that the region- and layer-specific innervation pattern develops through dynamic organization and reorganization processes occurring between P3 and P15. GFP-labeled callosal axons arrive in the white matter of the 17/18 border by P3 but do not invade the cortical plate until P5. This time lag corresponds with the previously described waiting period, during which growing axons explore and locate their target area for innervation (AggounZouaoui et al., 1996). Reducing cellular excitability of callosal projection neurons did not disturb the area-specific innervation pattern, implying that the process of region-specific axon targeting does not require neuronal activity. Thus, there might be some "positional cues" in the cortex that allow callosal axons to distinguish the 17/18 border region from adjacent areas.

A new finding is that the process of extensive growth of callosal axon arbors between $\mathrm{P} 7$ and $\mathrm{P} 15$ requires the activity of the projection neuron. During normal development, the density of callosal axon arbors and terminals in layers 1-3 increased dramatically between $\mathrm{P} 7$ and P15 (Figs. $2 B, 5 C$ ). This period of initial formation and extensive axon arborization was sensitive to manipulation of neuronal activity (Fig. 5). Previous studies have shown a requirement for vision in the organization of callosal connections in cat and hamster VC (Innocenti, et al., 1985; Fish, et al., 1991). However, a very long period of visual deprivation (neonatal to adulthood) is required to induce such changes. In contrast, by directly reducing the excitability of cortical neurons, we demonstrate that just a few days of activity blockade during the initial stages of callosal axon development are sufficient to alter projection patterns.

Neuronal activity in the cortex (spontaneous, visually driven, or both) may also be required for the reorganization process in which overabundant axonal arbors are selectively eliminated (Innocenti and Price, 2005). Indeed, exuberant growth followed by partial elimination of arbors in individual callosal axon fibers has been observed in the cat VC (Innocenti, 1995). In this study, we did not detect such reorganization process in the mouse VC. Because our study labels massive numbers of callosal axon fibers, reorganization of individual axon fibers might have been overlooked. Future work aimed to trace individual axons will clarify whether the reorganization process exists in mouse (Olavarria and Van Sluyters, 1984) and the role of neuronal activity in that process.

\section{Mechanism for activity-dependent axonal projection}

The present study demonstrates a crucial role of the activity of the projection neurons in their axonal development. To show activity dependence of cortical wiring, many previous studies both in vivo and in vitro have used tetrodotoxin (TTX) (a blocker of voltagesensitive sodium channels) as a tool to suppress electrical activity of cortical neurons (Herrmann and Shatz, 1995; Ruthazer and Stryker, 1996; Dantzker and Callaway, 1998; Butler et al., 2001; Uesaka et al., 2005). TTX infused in the brain or mixed in the slice culture medium suppresses neuronal activity globally, that is, in both presynaptic and postsynaptic neurons. In contrast, we used Kir2.1 for selective activity blockade of presynaptic or postsynap- tic neurons and found differential effects on the formation of cortical connections.

The currently prevailing view is that coordinated presynaptic and postsynaptic activity is required for neuronal connection development (Katz and Shatz, 1996). Assuming that presynaptic activity has a role only in synapse formation, postsynaptic activity blockade could have similar inhibitory effects on callosal connection development. This, however, was not the case. Our observation that activity blockade in projection neurons (i.e., presynaptic activity blockade) is more detrimental to their axonal development than postsynaptic activity blockade may indicate that the activity of the projection neuron has developmental roles other than synapse formation. In the chick spinal motoneuron axon projections, Hanson and Landmesser $(2004,2006)$ have recently shown that activity in projection neurons is required for their correct axonal pathfinding and fasciculation, a developmental process well before they contact postsynaptic targets. A similar developmental role for the activity of the projection neuron has also been shown in the mammalian olfactory system (Yu et al., 2004; Serizawa et al., 2006). We did not observe an apparent abnormality in the fasciculation or pathfinding of activityblocked callosal axons (Fig. 4), but they were unable to branch extensively after reaching the target layers (Fig. 5). Neuronal activity may influence the rate of axonal branching through intrinsic (e.g., regulation of cytoskeleton rearrangement) or extrinsic (e.g., recognition of environmental cues in the target layers) mechanisms. It is worth noting that blocking neuronal activity was most detrimental to the terminal axon arbors in layers 1-3 (Figs. 3, 5). It is shown that individual axons give rise to branches in both layers 5 and 2/3 (in cat VC) (Aggoun-Zouaoui et al., 1996). Selective reduction of terminal arborizations in layers $1-3$ implies that mechanisms for generation and maturation of axon arbors differ between layers (Butler et al., 2001).

Our observation that postsynaptic activity blockade had little effect on the overall innervation pattern of presynaptic callosal axons (Fig. 7) may seem contradictory to the consensus that synaptic activity plays a role in neuronal connection development (Meyer and Smith, 2006; Ruthazer et al., 2006). Several explanations can be considered for this observation. First, in this study, Kir2.1 overexpression did not entirely suppress the electrical activity of postsynaptic neurons through development (Fig. 3B). Second, not all layer 2/3 neurons expressed Kir2.1 in our postsynaptic activity-blockade experiments: judged from the pattern of DsRed2 expression, activity blockade was made in approximately half of layer 2/3 neurons (supplemental Fig. 4, available at www. jneurosci.org as supplemental material). Untransfected neurons in layer $2 / 3$ and other cortical layers could be the substrate for triggering presynaptic axon arbor growth. Third, because this experiment labels massive numbers of axon fibers, more subtle changes in the morphology of individual axons might have been overlooked. Thus, our results do not exclude a possibility that postsynaptic activity is involved in the callosal connection formation. Recently developed molecular tools that can alter the level or pattern of neuronal activity in a temporally controlled manner (Yamamoto et al., 2003; Callaway, 2005; Deisseroth et al., 2006; Herlitze and Landmesser, 2007) will be useful in elucidating the mechanism for activity-dependent synapse formation between callosal projection neurons and their postsynaptic targets.

\section{A mutant Kir2.1 channel affects callosal axon projections}

Kir2.1 is expressed in cardiac myocytes, as well as in neurons, and is essential for controlling membrane excitability (Jongsma and Wilders, 2001; Lopatin and Nichols, 2001). Mutations in the gene 
that encodes the Kir2.1 protein are responsible for Andersen syndrome, a disease associated with periodic skeletal muscle paralysis and cardiac arrhythmia (Plaster et al., 2001; Tristani-Firouzi et al., 2002). Most of these mutations result in loss-of-function with dominant-negative suppression of channel activity, which accounts for the autosomal dominant inheritance of the syndrome (Tristani-Firouzi et al., 2002; Bendahhou et al., 2003). In addition, a gain-of-function mutation (V93I) is reported in families with atrial fibrillation, a cardiac disease characterized by rapid and irregular activation of the atrium (Xia et al., 2005). Phenotypes of these Kir2.1 mutations have been extensively studied in the heart, but consequences in the brain have yet to be explored. To our knowledge, the present study is the first to reveal the possibility that patients carrying a mutation in Kir2.1 may have deficits in cortical connectivity. Overexpression of wild-type Kir2.1 in the heart induces multiple abnormalities in cardiac excitability (Miake et al., 2003; Li et al., 2004). Our findings suggest that enhanced Kir2.1 channel activity through overexpression of wild-type channels or gain-of-function mutant channels is also detrimental to the formation of interhemispheric connections in the brain.

Conversely, no apparent defects were observed in the development and axonal projection pattern of callosal neurons expressing dominant-negative Kir2.1 mutants (144$146 \mathrm{GYG} \rightarrow \mathrm{AAA}, \mathrm{D} 71 \mathrm{~V}$, and del314-315SY). These mutants show strong dominant-negative effects on endogenous Kir2 channel activity when expressed in cardiac myocytes (Miake et al., 2003); therefore, they are likely to inhibit the Kir2 channel activity in callosal projection neurons. The mechanism of Kir2.1 regulation of membrane excitability may differ between cardiac myocytes and neurons. Our results suggest that, despite the severe cardiac manifestations (i.e., Andersen syndrome), patients with these mutations are unlikely to have deficits in interhemispheric connection development.

Kir2.1 is expressed in layer 2/3 cortical neurons (presumably including callosal projection neurons) during perinatal and postnatal periods (Karschin and Karschin, 1997), but what role this channel has in these neurons remains unclear. $\mathrm{K}^{+}$channels open at the resting membrane potential (such as Kir2.1) are thought to be critically involved in the maturation and connection formation of neuronal cells by regulating the membrane potential and excitability (Nakanishi and Okazawa, 2006). No apparent phenotype in our dominant-negative mutant experiments implies that $\mathrm{K}^{+}$channels other than Kir2.1 are sufficient to regulate the excitability in callosal projection neurons. Although this study shows that a certain level of activity in callosal neurons is crucial for their axonal projections, the precise mechanism of their regulation of excitability during development awaits additional investigation.

\section{References}

Adelsberger H, Garaschuk O, Konnerth A (2005) Cortical calcium waves in resting newborn mice. Nat Neurosci 8:988-990.

Aggoun-Zouaoui D, Innocenti GM (1994) Juvenile visual callosal axons in kittens display origin- and fate-related morphology and distribution of arbors. Eur J Neurosci 6:1846-1863.

Aggoun-Zouaoui D, Kiper DC, Innocenti GM (1996) Growth of callosal terminal arbors in primary visual areas of the cat. Eur J Neurosci 8:1132-1148.

Antonini A, Stryker MP (1993) Rapid remodeling of axonal arbors in the visual cortex. Science 260:1819-1821.

Antonini A, Stryker MP (1996) Plasticity of geniculocortical afferents following brief or prolonged monocular occlusion in the cat. J Comp Neurol 369:64-82.

Bendahhou S, Donaldson MR, Plaster NM, Tristani-Firouzi M, Fu YH, Ptacek LJ (2003) Defective potassium channel Kir2.1 trafficking underlies Andersen-Tawil syndrome. J Biol Chem 278:51779-51785.
Blakemore C, Diao YC, Pu ML, Wang YK, Xiao YM (1983) Possible functions of the interhemispheric connexions between visual cortical areas in the cat. J Physiol (Lond) 337:331-349.

Burrone J, O'Byrne M, Murthy VN (2002) Multiple forms of synaptic plasticity triggered by selective suppression of activity in individual neurons. Nature 420:414-418.

Butler AK, Dantzker JL, Shah RB, Callaway EM (2001) Development of visual cortical axons: layer-specific effects of extrinsic influences and activity blockade. J Comp Neurol 430:321-331.

Callaway EM (2005) A molecular and genetic arsenal for systems neuroscience. Trends Neurosci 28:196-201.

Callaway EM, Katz LC (1991) Effects of binocular deprivation on the development of clustered horizontal connections in cat striate cortex. Proc Natl Acad Sci USA 88:745-749.

Cusick CG, Lund RD (1982) Modification of visual callosal projections in rats. J Comp Neurol 212:385-398.

Dantzker JL, Callaway EM (1998) The development of local, layer-specific visual cortical axons in the absence of extrinsic influences and intrinsic activity. J Neurosci 18:4145-4154.

Deisseroth K, Feng G, Majewska AK, Miesenbock G, Ting A, Schnitzer MJ (2006) Next-generation optical technologies for illuminating genetically targeted brain circuits. J Neurosci 26:10380-10386.

Fish SE, Rhoades RW, Bennett-Clarke CA, Figley B, Mooney RD (1991) Organization, development and enucleation-induced alterations in the visual callosal projection of the hamster: single axon tracing with Phaseolus vulgaris leucoagglutinin and Di-I. Eur J Neurosci 3:1255-1270.

Fukumitsu H, Ohtsuka M, Murai R, Nakamura H, Itoh K, Furukawa S (2006) Brain-derived neurotrophic factor participates in determination of neuronal laminar fate in the developing mouse cerebral cortex. J Neurosci 26:13218-13230.

Gavrieli Y, Sherman Y, Ben-Sasson SA (1992) Identification of programmed cell death in situ via specific labeling of nuclear DNA fragmentation. J Cell Biol 119:493-501.

Goodman CS, Shatz CJ (1993) Developmental mechanisms that generate precise patterns of neuronal connectivity. Cell [Suppl] 72:77-98.

Hanson MG, Landmesser LT (2004) Normal patterns of spontaneous activity are required for correct motor axon guidance and the expression of specific guidance molecules. Neuron 43:687-701.

Hanson MG, Landmesser LT (2006) Increasing the frequency of spontaneous rhythmic activity disrupts pool-specific axon fasciculation and pathfinding of embryonic spinal motoneurons. J Neurosci 26:12769-12780.

Hatanaka Y, Hisanaga S, Heizmann CW, Murakami F (2004) Distinct migratory behavior of early- and late-born neurons derived from the cortical ventricular zone. J Comp Neurol 479:1-14.

Herlitze S, Landmesser LT (2007) New optical tools for controlling neuronal activity. Curr Opin Neurobiol 17:87-94.

Herrmann K, Shatz CJ (1995) Blockade of action potential activity alters initial arborization of thalamic axons within cortical layer 4. Proc Natl Acad Sci USA 92:11244-11248.

Horikawa K, Takeichi M (2001) Requirement of the juxtamembrane domain of the cadherin cytoplasmic tail for morphogenetic cell rearrangement during myotome development. J Cell Biol 155:1297-1306.

Hua JY, Smear MC, Baier H, Smith SJ (2005) Regulation of axon growth in vivo by activity-based competition. Nature 434:1022-1026.

Hubel DH, Wiesel TN (1967) Cortical and callosal connections concerned with the vertical meridian of visual fields in the cat. J Neurophysiol 30:1561-1573.

Innocenti GM (1995) Exuberant development of connections, and its possible permissive role in cortical evolution. Trends Neurosci 18:397-402.

Innocenti GM, Frost DO (1979) Effects of visual experience on the maturation of the efferent system to the corpus callosum. Nature 280:231-234.

Innocenti GM, Price DJ (2005) Exuberance in the development of cortical networks. Nat Rev Neurosci 6:955-965.

Innocenti GM, Frost DO, Illes J (1985) Maturation of visual callosal connections in visually deprived kittens: a challenging critical period. J Neurosci 5:255-267.

Innocenti GM, Clarke S, Kraftsik R (1986) Interchange of callosal and association projections in the developing visual cortex. J Neurosci 6:1384-1409.

Jacobson S, Trojanowski JQ (1974) The cells of origin of the corpus callosum in rat, cat and rhesus monkey. Brain Res 74:149-155. 
Johns DC, Marx R, Mains RE, O’Rourke B, Marban E (1999) Inducible genetic suppression of neuronal excitability. J Neurosci 19:1691-1697.

Jongsma HJ, Wilders R (2001) Channelopathies: Kir2.1 mutations jeopardize many cell functions. Curr Biol 11:R747-R750.

Karschin C, Karschin A (1997) Ontogeny of gene expression of Kir channel subunits in the rat. Mol Cell Neurosci 10:131-148.

Katz LC, Crowley JC (2002) Development of cortical circuits: lessons from ocular dominance columns. Nat Rev Neurosci 3:34-42.

Katz LC, Shatz CJ (1996) Synaptic activity and the construction of cortical circuits. Science 274:1133-1138.

Kawaguchi SY, Hirano T (2006) Integrin $\alpha 3 \beta 1$ suppresses long-term potentiation at inhibitory synapses on the cerebellar Purkinje neuron. Mol Cell Neurosci 31:416-426.

Khazipov R, Luhmann HJ (2006) Early patterns of electrical activity in the developing cerebral cortex of humans and rodents. Trends Neurosci 29:414-418.

LeVay S, Wiesel TN, Hubel DH (1980) The development of ocular dominance columns in normal and visually deprived monkeys. J Comp Neurol 191:1-51.

Li J, McLerie M, Lopatin AN (2004) Transgenic upregulation of IK1 in the mouse heart leads to multiple abnormalities of cardiac excitability. Am J Physiol Heart Circ Physiol 287:H2790-H2802.

Lindwall C, Fothergill T, Richards LJ (2007) Commissure formation in the mammalian forebrain. Curr Opin Neurobiol 17:3-14.

Lopatin AN, Nichols CG (2001) Inward rectifiers in the heart: an update on $\mathrm{I}_{\mathrm{K} 1}$. J Mol Cell Cardiol 33:625-638.

Lopez-Bendito G, Molnar Z (2003) Thalamocortical development: how are we going to get there? Nat Rev Neurosci 4:276-289.

Lowel S, Singer W (1992) Selection of intrinsic horizontal connections in the visual cortex by correlated neuronal activity. Science 255:209-212.

Matsuda T, Cepko CL (2007) Controlled expression of transgenes introduced by in vivo electroporation. Proc Natl Acad Sci USA 104:1027-1032.

McEvilly RJ, de Diaz MO, Schonemann MD, Hooshmand F, Rosenfeld MG (2002) Transcriptional regulation of cortical neuron migration by POU domain factors. Science 295:1528-1532.

Mesulam MM (1978) Tetramethyl benzidine for horseradish peroxidase neurohistochemistry: a non-carcinogenic blue reaction product with superior sensitivity for visualizing neural afferents and efferents. J Histochem Cytochem 26:106-117.

Meyer MP, Smith SJ (2006) Evidence from in vivo imaging that synaptogenesis guides the growth and branching of axonal arbors by two distinct mechanisms. J Neurosci 26:3604-3614.

Miake J, Marban E, Nuss HB (2003) Functional role of inward rectifier current in heart probed by Kir2.1 overexpression and dominant-negative suppression. J Clin Invest 111:1529-1536.

Miyashita T, Kubo Y (1997) Localization and developmental changes of the expression of two inward rectifying $\mathrm{K}^{+}$-channel proteins in the rat brain. Brain Res 750:251-263.

Nakanishi S, Okazawa M (2006) Membrane potential-regulated $\mathrm{Ca}^{2+}$ signalling in development and maturation of mammalian cerebellar granule cells. J Physiol (Lond) 575:389-395.

Niwa H, Yamamura K, MiyazakiJ (1991) Efficient selection for high-expression transfectants with a novel eukaryotic vector. Gene 108:193-199.

Olavarria J, Montero VM (1984) Relation of callosal and striate-extrastriate cortical connections in the rat: morphological definition of extrastriate visual areas. Exp Brain Res 54:240-252.

Olavarria JF, Safaeian P (2006) Development of callosal topography in visual cortex of normal and enucleated rats. J Comp Neurol 496:495-512.

Olavarria J, Van Sluyters RC (1984) Callosal connections of the posterior neocortex in normal-eyed, congenitally anophthalmic, and neonatally enucleated mice. J Comp Neurol 230:249-268.

Olavarria J, Malach R, Van Sluyters RC (1987) Development of visual callosal connections in neonatally enucleated rats. J Comp Neurol 260:321-348

Owens DF, Boyce LH, Davis MB, Kriegstein AR (1996) Excitatory GABA responses in embryonic and neonatal cortical slices demonstrated by gramicidin perforated-patch recordings and calcium imaging. J Neurosci 16:6414-6423.

Plaster NM, Tawil R, Tristani-Firouzi M, Canun S, Bendahhou S, Tsunoda A, Donaldson MR, Iannaccone ST, Brunt E, Barohn R, Clark J, Deymeer F, George Jr AL, Fish FA, Hahn A, Nitu A, Ozdemir C, Serdaroglu P, Subramony SH, Wolfe G, Fu YH, Ptacek LJ (2001) Mutations in Kir2.1 cause the developmental and episodic electrical phenotypes of Andersen's syndrome. Cell 105:511-519.

Price DJ, Kennedy H, Dehay C, Zhou L, Mercier M, Jossin Y, Goffinet AM, Tissir F, Blakey D, Molnar Z (2006) The development of cortical connections. Eur J Neurosci 23:910-920.

Rhoades RW, Dellacroce DD (1980) Neonatal enucleation induces an asymmetric pattern of visual callosal connections in hamsters. Brain Res 202:189-195.

Ruthazer ES, Cline HT (2004) Insights into activity-dependent map formation from the retinotectal system: a middle-of-the-brain perspective. J Neurobiol 59:134-146.

Ruthazer ES, Stryker MP (1996) The role of activity in the development of long-range horizontal connections in area 17 of the ferret. J Neurosci 16:7253-7269.

Ruthazer ES, Li J, Cline HT (2006) Stabilization of axon branch dynamics by synaptic maturation. J Neurosci 26:3594-3603.

Saito T, Nakatsuji N (2001) Efficient gene transfer into the embryonic mouse brain using in vivo electroporation. Dev Biol 240:237-246.

Serizawa S, Miyamichi K, Takeuchi H, Yamagishi Y, Suzuki M, Sakano H (2006) A neuronal identity code for the odorant receptor-specific and activity-dependent axon sorting. Cell 127:1057-1069.

Shatz CJ (1977) Anatomy of interhemispheric connections in the visual system of Boston Siamese and ordinary cats. J Comp Neurol 173:497-518.

Stryker MP, Harris WA (1986) Binocular impulse blockade prevents the formation of ocular dominance columns in cat visual cortex. J Neurosci 6:2117-2133.

Stryker MP, Antonini A (2001) Factors shaping the corpus callosum. J Comp Neurol 433:437-440.

Sur M, Rubenstein JL (2005) Patterning and plasticity of the cerebral cortex. Science 310:805-810.

Tabata H, Nakajima K (2001) Efficient in utero gene transfer system to the developing mouse brain using electroporation: visualization of neuronal migration in the developing cortex. Neuroscience 103:865-872.

Torii M, Levitt P (2005) Dissociation of corticothalamic and thalamocortical axon targeting by an EphA7-mediated mechanism. Neuron 48:563-575.

Tristani-Firouzi M, Jensen JL, Donaldson MR, Sansone V, Meola G, Hahn A, Bendahhou S, Kwiecinski H, Fidzianska A, Plaster N, Fu YH, Ptacek LJ, Tawil R (2002) Functional and clinical characterization of KCNJ2 mutations associated with LQT7 (Andersen syndrome). J Clin Invest 110:381-388.

Uesaka N, Hirai S, Maruyama T, Ruthazer ES, Yamamoto N (2005) Activity dependence of cortical axon branch formation: a morphological and electrophysiological study using organotypic slice cultures. J Neurosci 25:1-9.

Van Essen DC, Newsome WT, Bixby JL (1982) The pattern of interhemispheric connections and its relationship to extrastriate visual areas in the macaque monkey. J Neurosci 2:265-283.

Wiesel TN (1982) Postnatal development of the visual cortex and the influence of environment. Nature 299:583-591.

Xia M, Jin Q, Bendahhou S, He Y, Larroque MM, Chen Y, Zhou Q, Yang Y, Liu Y, Liu B, Zhu Q, Zhou Y, Lin J, Liang B, Li L, Dong X, Pan Z, Wang R, Wan H, Qiu W, Xu W, Eurlings P, Barhanin J, Chen Y (2005) A Kir2.1 gain-of-function mutation underlies familial atrial fibrillation. Biochem Biophys Res Commun 332:1012-1019.

Yamamoto M, Wada N, Kitabatake Y, Watanabe D, Anzai M, Yokoyama M, Teranishi Y, Nakanishi S (2003) Reversible suppression of glutamatergic neurotransmission of cerebellar granule cells in vivo by genetically manipulated expression of tetanus neurotoxin light chain. J Neurosci 23:6759-6767.

Yu CR, Power J, Barnea G, O’Donnell S, Brown HE, Osborne J, Axel R, Gogos JA (2004) Spontaneous neural activity is required for the establishment and maintenance of the olfactory sensory map. Neuron 42:553-566.

Yuste R, Nelson DA, Rubin WW, Katz LC (1995) Neuronal domains in developing neocortex: mechanisms of coactivation. Neuron 14:7-17.

Zaritsky JJ, Eckman DM, Wellman GC, Nelson MT, Schwarz TL (2000) Targeted disruption of Kir2.1 and Kir2.2 genes reveals the essential role of the inwardly rectifying $\mathrm{K}^{+}$current in $\mathrm{K}^{+}$-mediated vasodilation. Circ Res 87:160-166.

Zufferey PD, Jin F, Nakamura H, Tettoni L, Innocenti GM (1999) The role of pattern vision in the development of cortico-cortical connections. Eur J Neurosci 11:2669-2688. 